\title{
PRACTICAL PROCESS CHARACTERISATION FOR HOT-STAMPING REGARDING THE HEAT TRANSFER COEFFICIENT USING A NUMERICAL AND EXPERIMENTAL COUPLED METHOD
}

\author{
${ }^{1}$ Bernd-Arno BEHRENS, ${ }^{1}$ Kai BRUNOTTE, ${ }^{1}$ Hendrik WESTER, ${ }^{1}$ Felix MÜLLER \\ 1'Institute of Forming Technology and Machines, An der Universität 2, 30823 Garbsen, Germany, EU \\ f.mueller@ifum.uni-hannover.de
}

https://doi.org/10.37904/metal.2020.3522

\begin{abstract}
Due to the efficient combination of a forming step with a consecutive heat treatment, hot-stamping has become an established technology for the production of high strength steel parts in the automotive industry. In the beginning, sheets are heated above austenitisation temperature and held in order to obtain a fully austenised microstructure, then formed and instantly quenched in the forming tool. To achieve the desired increase in tensile strength for the widely used manganese boron steel $22 \mathrm{MnB} 5$, cooling rates of at least $27 \mathrm{~K} / \mathrm{s}$ are necessary. This requirement sets a high demand on the numerical process simulation in order to being able to predict the occurrence of component or process errors with a high degree of certainty. To achieve this, the exact knowledge of the local heat transfer coefficient is necessary, which dominantly determines the temperature distribution within the work piece and the die. Since there is none standardised test method for the determination of heat transfer coefficients exists, a practical test method is presented in this study. In addition to the use of a divisible temperature-measuring stamp, the method is based on a close coupling of practical experiment and iterative numerical simulation. With the method and tools shown in the scope of this paper, the heat transfer coefficient could be successfully determined as a function of contact pressure and tool start temperature, taking the process route of hot-stamping into account. Results are compared with literature knowledgeorder to demonstrate the performance of the determination method.
\end{abstract}

Keywords: Hot-stamping, heat transfer coefficient, experimental determination method, numerical coupling

\section{INTRODUCTION}

Due to continuously increasing legal requirements regarding the reduction of emissions in the automotive sector, the continuous weight reduction of vehicle bodies is a main goal of OEM [1]. Hot-stamping has been industrially established as a manufacturing process since the 1970s and has been the subject of numerous publications. After pre-cutting, the initial blank is austenitised at temperatures above $900{ }^{\circ} \mathrm{C}$ in the furnace and then transferred to the press, formed and directly heat-treated by continuously cooled tools [2]. Despite many years of industrial application, this process still presents challenges and methodical development potential. In order to meet complex mechanical requirement profiles, many production steps and process components are currently being examined for improvements or alternatives. Because of the phase transformation behaviour of $22 \mathrm{MnB} 5$, a cooling rate of at least $27 \mathrm{~K} / \mathrm{s}-30 \mathrm{~K} / \mathrm{s}$ must be accomplished in order to ensure a complete transformation of the austenite into the high strength- and hardness-featured martensite [3]. While industrial focus so far has been mainly on achieving this process requirement, numerical process simulation enables precise planning of the locally different temperature routes and therefore the specific utilisation for individual control of part properties. Concepts designed in this way are classified as tailored tempering. FE simulations are an indispensable tool during the process design due to the high demands placed on temperature control accuracy. In order to ensure specific cooling rates during quenching numerically, it is necessary to characterise the thermal conditions of this process part. Since the major part of the heat transfer takes place shortly after the initial contact between the tool and the sheet metal [4], the heat transfer coefficient (HTC) is of particular 
importance to avoid prediction errors during process simulations [5]. Subsequently, a practical method for characterising the heat transfer coefficient (HTC) is presented.

\section{METHODOLOGY}

Investigations on the HTC have been a widespread subject of research. However, since there is no conductive standard, a variety of approaches exists with regard to the experimental execution and the subsequent data evaluation. Altan et al. [6] presented the basic experimental setup consisting of two stamps in 1987. After that, Malinowski et al. [7] used an idealised finite element approach for the HTC determination. Merklein et al. [8] investigated the HTC under the process-adapted conditions of hot-stamping with an analytical calculation approach based on the cooling behaviour of the sheet sample. Caron et al. [9] showed an inverse calculation method of the HTC under consideration of the relevant temperature-dependent material properties and applied it to the tool approach- as well as the tool closure phase of the test. Conclusively, there is an agreement in all investigations that the HTC is strongly dependent on the contact pressure during the loading and the die temperature. In the context of this work, a practical combined experimental and numerical determination method is presented and explained focusing on an accuracy improvement of the temperature recording during the experiment. The applied combined determination approach is based on the implementation of an experiment and a parallel carried out FE simulation (Figure 1). In the experiment, temperature profiles are recorded under variation of the contact pressure, while in the simulation a digital twin of the experiment is build up to determine temperature profiles in relation to the HTC value. After the execution of both investigations, resulting temperature profiles are directly compared. If a data match is found, the corresponding contact pressure value is assigned to the HTC value set in the appropriate simulation.

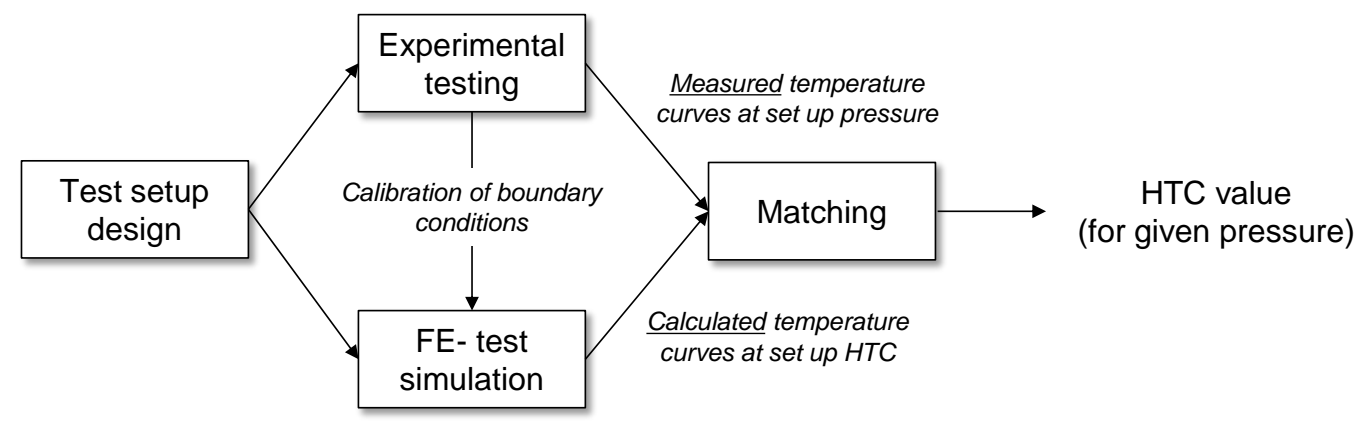

Figure 1 Method for the determination of the HTC Value

The general test design to determine the HTC under hot-stamping conditions is an improved version of the approach described by Altan et al. [6]. Two heatable punches $(\varnothing 60 \mathrm{~mm})$ are used to apply contact pressures of up to $100 \mathrm{MPa}$ in a forming simulator by Instron (Figure 2). Heating bands are used to preheat the tool parts, enabling a homogeneous temperature field to be applied. As suggested by Merklein et al. [8], springloaded spacer pins were inserted in the lower die to prevent premature contact of the blank with the lower die before the tool is completely closed. The central aspect of the test tool for determining the HTC is the introduction of near-surface thermocouples. It is currently common practice to drill holes at a defined distance from the punch surface which are fitted with mantle thermocouples. Even though this method is applicable in general, it offers several problems. The contact between the mantle and the bore wall creates an additional heat transfer, which could be optimised with appropriate heat conducting paste, but continues to induce inertia in the temperature measurement. This is a disadvantage while recording sudden temperature fluctuations, as can be expected after the heated blank has been inserted in the tool. Furthermore, during the numerical determination of the HTC, it is decisive to set the correct position where the temperature curve was recorded. In addition to measuring the drilling depth, there is no other way to verify the exact position of the thermocouple in the punch with the current method. Finally, the drilling of a borehole leads to a disturbance of the temperature 
field, which has to be corrected with the compensation method presented by Caron et al. [9]. In order to address these disadvantages, a new approach is presented in the context of this work consisting of a design update for the lower stamp (Figure 2, C). This consists of two separable halves, whereby three milled measuring channels (width: $2 \mathrm{~mm}$, depth: $2 \mathrm{~mm}$ ) were inserted in one stamp half. These have a distance of $0.5 \mathrm{~mm}$, $1.0 \mathrm{~mm}$ and $3.0 \mathrm{~mm}$ from the stamp surface. A type $\mathrm{K}$ thermocouple is welded into the end of each of these channels. Thermocouples inserted in this way are material-locked to the measuring point and are thus able to record highly dynamic temperature changes because of the inherent high measuring-response time. In addition, since the welded joint is accessible, the exact measuring position can be verified afterwards.
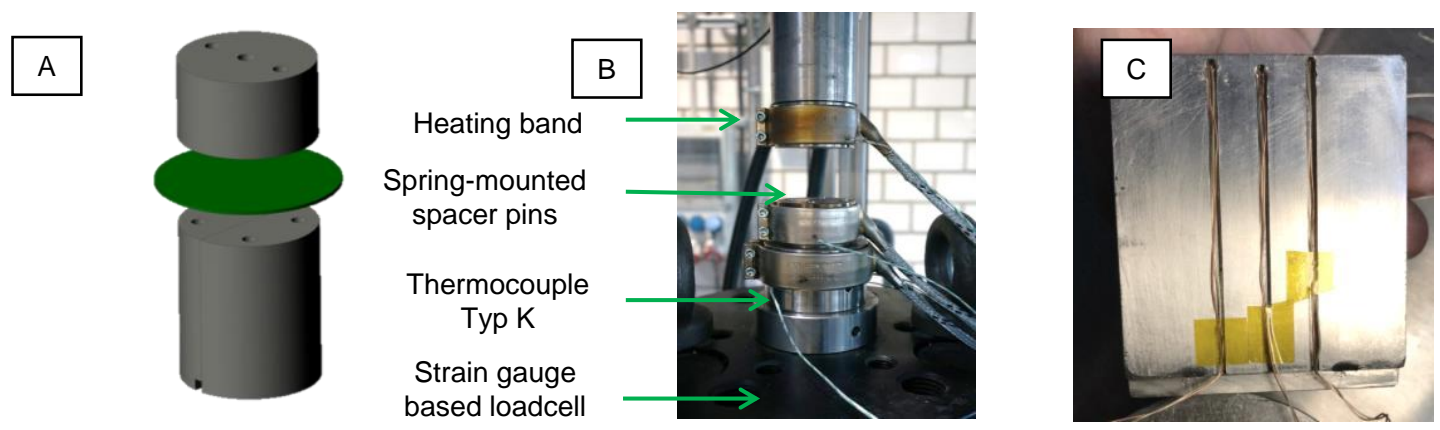

Figure 2 Schematic HTC test setup design (A), experimental test setup (B) and separable measuring punch half $(C)$

During testing, these thermocouples are connected to a multi-channel measuring amplifier by HBM set to a measuring frequency of $300 \mathrm{~Hz}$. During the investigation, circular 22MnB5 blanks with AISi coating, a thickness of $1.5 \mathrm{~mm}$ and a diameter of $80 \mathrm{~mm}$ are used. A type $\mathrm{K}$ thermocouple is attached to the surface in a groove. The blank diameter is selected bigger then the stamp diameter to ensure that the heat dissipation into the gripping tool during the transfer is not interfering the contact zone of the sheet to the punches. Before each test, blanks are heated in a separate furnace at $950^{\circ} \mathrm{C}$ for $5 \mathrm{~min}$ to ensure complete austenitisation. The tool start temperature is set to $100^{\circ} \mathrm{C}$. Subqequently, the blanks are manually transferred and the die is closed for $30 \mathrm{~s}$ at a defined press force.

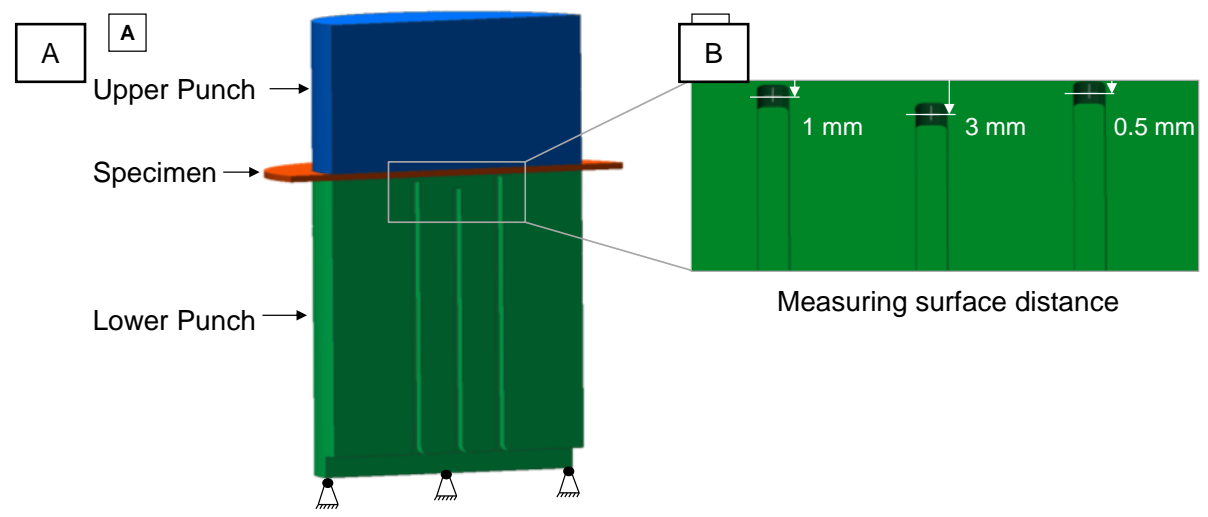

Figure $3 \mathrm{FE}-$ Model for investigating the HTC Value (A) and detailed section of the measuring channels for the evaluation of temperatures $(B)$

Parallel to the experimental investigations, a FE-model as shown in Figure $\mathbf{3}$ is built up on the basis of the used CAD data within the framework of Simufact.forming 15. A 3D half section approach with solid elements is chosen. This allows for the consideration of the milled measuring channels, so that the temperature correction described by Caron et al. [10] is not necessary. An ideal contact between all surfaces is provided via contact tables. The transfer phase is taken into account by setting the blank start temperature to $825^{\circ} \mathrm{C}$. 
This value was consistently experimentally recorded after a manual transfer time of approx. $6 \mathrm{~s}$. For the blank, phase-depended thermal material data obtained from Oberpriller et al. [11] and Kießling [12] are used. For the punches (Tool steel: 1.2367 / X38CrMoV5-3 / H13modify), the thermal conductivity was set to $30.8 \mathrm{~W} /(\mathrm{mK})$ and the specific heat capacity was set to $460 \mathrm{~J} /(\mathrm{kgK})$ obtained from Wilzer et al.[13]. With this model, a series of simulations is carried out in which the HTC value is gradually increased from $1 \mathrm{~kW} /\left(\mathrm{m}^{2} \mathrm{~K}\right)$ up to $20 \mathrm{~kW} /\left(\mathrm{m}^{2} \mathrm{~K}\right)$. After the respective evaluation of the individual measuring channels, the temperature curves recorded in the real test are used for the comparison method as initially described.

\section{HTC DETERMINATION RESULTS}

The method presented below is used as an example for a temperature data set, recorded at a contact pressure of $40 \mathrm{MPa}$. The temperature measurement in Figure 4 (A) starts by taking the blank out of the furnace. After the above-mentioned transfer time, the closure time begins which is set to the timestamp $t=0 \mathrm{~s}$. This closure is indicated by a sudden drop in the blank surface temperature to approx. $250{ }^{\circ} \mathrm{C}$ after $4 \mathrm{~s}$. At the same time, the measured temperature in the measuring channel, $0.5 \mathrm{~mm}$ below the surface, already reaches a peak temperature of $300^{\circ} \mathrm{C}$ after less than $0.5 \mathrm{~s}$ of the closure start $(6.5 \mathrm{~s}$ total time). After reaching the maximum temperature, all measurements at this location show a distinct fluctuation caused by the impact of the tool closure. The intensity of this aberration rises with increasing contact pressure. Additionaly, the temperature measurement in the deepest channel $(3 \mathrm{~mm})$ shows time-delayed and reduced temperature peaks and is also unaffected by the impact of the tool closure. Subsequently, the sensitivity of the FE model to the variation of the HTC value is shown in Figure 4 (B, coloured lines). It is visible that low HTC values in the measuring channel $0.5 \mathrm{~mm}$ below the surface lead to a distinct variation of the resulting maximum temperature as well as the heating rates. However, the amount of the influence on the peak temperatures reduces with rising HTC values.
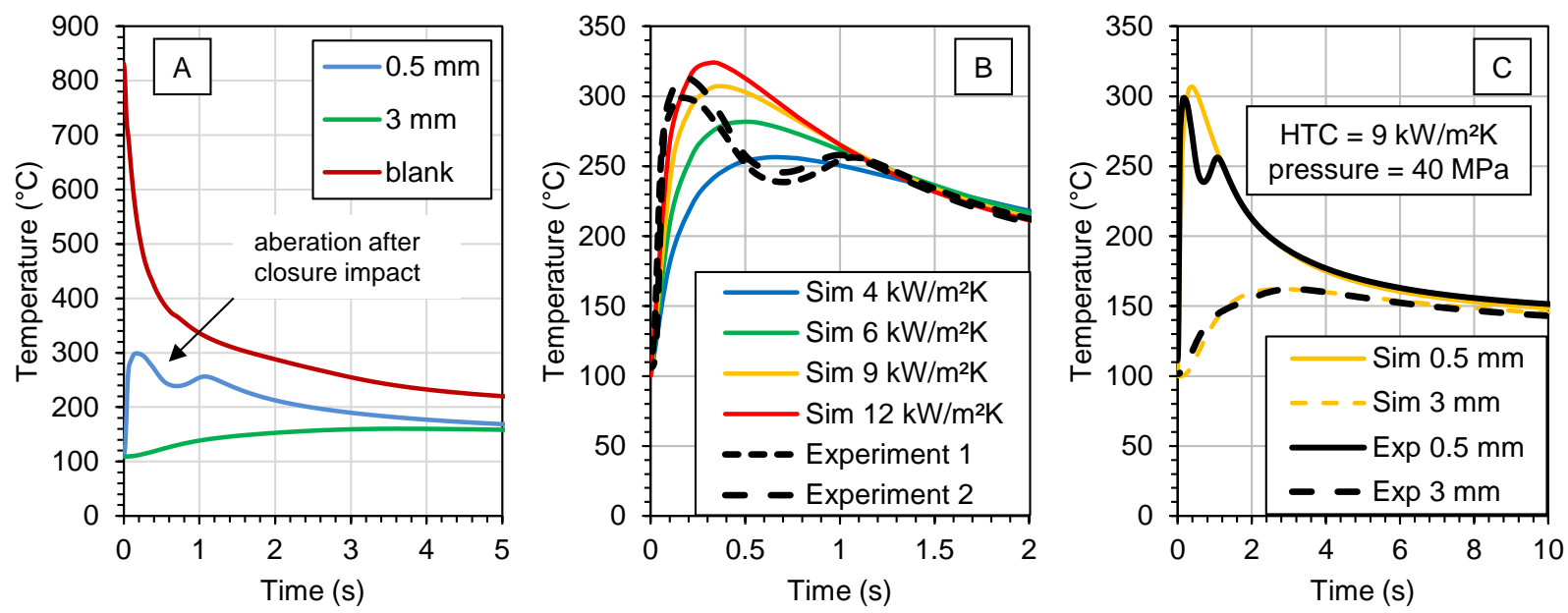

Figure 4 Temperature measurement of the blank and punch thermocouples at $40 \mathrm{MPa}$ contact pressure: Raw experimental data (A), HTC matching of the $0.5 \mathrm{~mm}$ measuring channel (B) and calculated temperature curves for $\mathrm{HTC}=9 \mathrm{~kW} /\left(\mathrm{m}^{2} \mathrm{~K}\right)(\mathrm{C})$

For the final determination of the HTC, Figure 4 (B, dashed lines) displays the temperature measurements of two experiments at a contact pressure of $40 \mathrm{MPa}$ in regard to the numerically calculated results. It becomes apparent that an $\mathrm{HTC}$ value between $9 \mathrm{~kW} /\left(\mathrm{m}^{2} \mathrm{~K}\right)$ and $12 \mathrm{~kW} /\left(\mathrm{m}^{2} \mathrm{~K}\right)$ is achieved in relation to the heating rates. If, on the other hand, the reached maximum temperature is compared, the HTC tends towards a slightly lower value, which can also be explained by inconsistencies during manual insertion of the blank. After the matching of an $\mathrm{HTC}$ value of $9 \mathrm{~kW} /\left(\mathrm{m}^{2} \mathrm{~K}\right)$ to the measurement at a contact pressure of $40 \mathrm{MPa}$, an additional validation step can be implemented by inspecting the temperature curve measured in the $3 \mathrm{~mm}$ deep channel. 
Figure $4(\mathrm{C})$ shows a comparison between the experimentally measured temperature curves over a longer period of time and the numerically generated data. While a good agreement of the data can be seen in general, especially the agreement of the $3 \mathrm{~mm}$ sub surface measuring channel confirms the material data of the punch in respect for the thermal conductivity. Subsequently, this procedure was used to investigate the influence of contact pressure in a range from $5 \mathrm{MPa}$ to $80 \mathrm{MPa}$. The maximum recorded temperature averaged values are shown in Figure $5(A)$ in respect to the left $y$-axis. While there is a strong relationship between the contact pressure and the temperature reading in the $0.5 \mathrm{~mm}$ sub surface measuring channel, the influence on the 3 $\mathrm{mm}$ sub surface measuring channel is comparatively low. Up to a contact pressure of $30 \mathrm{MPa}$, the maximum temperature recorded in the $0.5 \mathrm{~mm}$ channel rises linearly up to $275{ }^{\circ} \mathrm{C}$. After that, a jump in the average temperatures can be noted. Because of the evidently higher standard deviation of the measurement at $40 \mathrm{MPa}$, an overestimation has to be assumed. Because the measurements for this work were started at this pressure level with a freshly machined tool surface first, it can be concluded that alteration effect due to growing oxide scale on the tool surface could be the reason for the comparatively high measurement inaccuracy at this pressure level. Since the standard deviation at the other pressure levels is much lower, the alteration of the tool surface is negligible after the first measurements. The temperature measurement at a contact pressure of $80 \mathrm{MPa}$ exceeds the process relevance of hot stamping, but illustrates that the temperatures in the punch are reaching a saturation value. The HTC values determined with the described matching method are presented in Figure 5 (A) plotted on the right y-axis. The pressure behaviour of the HTC is consecutively comparable to the temperature findings. Furthermore, the HTC values are compared to the results in the literature quoted in this study (Figure 5, B). All studies show an agreement in a rising HTC value over the contact pressure. Since all studies are based on a non-standardised experimental method and data evaluation, the occurring deviations are rated as comparatively low. The determination method presented in this paper can therefore be recommended for process simulations with a distinct focus on the appearing tool surface temperatures with the emphasis on a high contact pressure range.
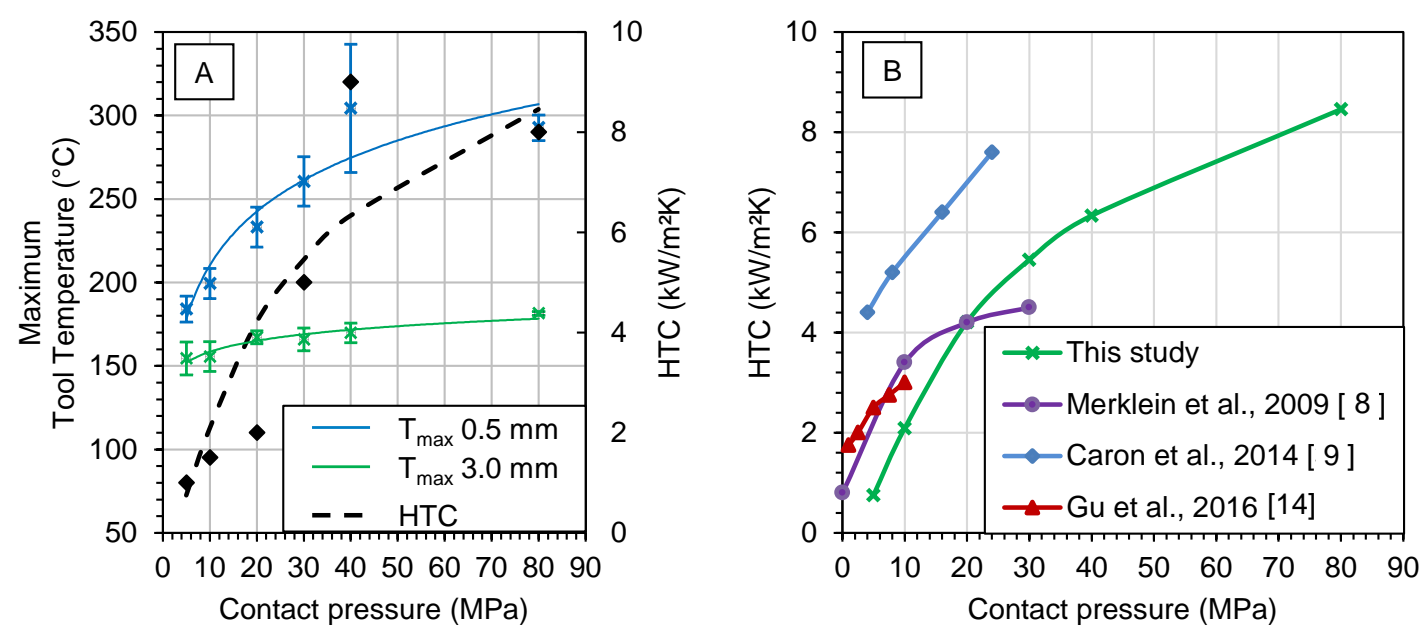

Figure 5 Maximum tool temperatures in regard to the contact pressure in combination with determined HTC values $(A)$ and Comparison with literature data $(B)$

\section{CONCLUSION}

For the quenching stage of a hot-stamping process, a practical method for obtaining heat transfer coefficients is presented. By designing a divisible stamping tool, welded thermocouples can be applied in measuring channels with defined spacing from the surface providing a verifiable measuring location and a fast measuring response time. Subsequently, a suitable FE-model is built up to map HTC values to specific pressure values with an iterative comparison method of the temperature values. Because of the specimen dimension in relation to the force potential of the testing machine, pressure ranges of the HTC in the literature could be extended. 
While this process window extension may not be relevant for common hot-stamping operations, it presents a valuable addition when special hot-stamping related operations are considered such as adding an additional joining step as presented by Stockburger et al. [15].

\section{ACKNOWLEDGEMENTS}

\section{The authors gratefully acknowledge the support the German Federation of Industrial Research Associations (AiF) within the project $19518 \mathrm{~N}$ for this research work.}

\section{REFERENCES}

[1] TURETTA, A., BRUSCHI, S., GHIOTTI, A. Investigation of 22MnB5 formability in hot stamping operations. Journal of Materials Processing Technology.2006, vol. 177, no. 1 - 3, pp. $396-400$.

[2] BEHRENS, B.-A., BACH, F.-W., DIEKAMP, M., HÜBNER, S., NÜRNBERGER, F., SCHRÖDTER, J., WOLF, L., MORITZ, J. Process Time Reduction of Hot Stamping by Means of Early Extraction from the Press, In 4th International Conference on Hot Sheet Metal Forming of High-Performance Steel. Luleå: LU Press, 2013, pp. 259 $-266$.

[3] CARON, E., DAUN, K.J., WELLS, M.A. Experimental characterisation of heat transfer coefficients during hot forming die quenching of boron steel. Metall. Mater. Trans. Vol. 44B, 2013, pp. 332 - 343.

[4] MORI, K., BARIANI, P.F., BEHRENS, B.-A., BROSIUS, A., BRUSCHI, S., MAENO, T., MERKLEIN, M., YANAGIMOTO, J. Hot stamping of ultra-high strength steel parts. CIRP Annals - Manufacturing Technology. 2017, vol. 66, no. 2, pp. 755 - 777.

[5] POLOZINE, A., SCHAEFFER, L. Influence of the inaccuracy of thermal contact conductance coefficient on the weighted-mean temperature calculated for a forged blank. J. Mater. Process. Technol. 2008, vol. 195, pp. 260 266.

[6] ALTAN, T., SEMIATIN, S.L., COLLINGS, E.W., WOOD, V.E. Determination of the Interface Heat Transfer Coefficient for Non-Isothermal Bulk-Forming Proceesses. Journal of Engineering for Industry. 1987, vol. 109, pp. 1-25.

[7] MALINOWSKI, Z., LENARD, J.G., DAVIES, M.E. A study of the heat-transfer coefficient as a function of temperature and pressure. Journal of Materials Processing Technologies. 1994, vol. 41, pp. 18-24.

[8] MERKLEIN, M., LECHLER, J., STOEHR, T. Investigations on the thermal behavior of ultra-high strength boron manganese steels within hot stamping. Int. J. Mater. Form., 2009, vol. 2, Suppl. 1, pp. 259 - 262.

[9] CARON, E., DAUN, K.J., WELLS, M.A. Experimental heat transfer coefficient measurements during hot forming die quenching of boron steel at high temperatures. International Journal of Heat and Mass Transfer.2014, vol. 71, pp. 396 - 404.

[10] Caron, E., Wells, M.A., Li, D. A Compensation Method for the Disturbance in the Temperature Field caused by Subsurface Thermocouples. Metallurgical and Materials Tansactions, 2006, vol. 37B, pp. 245-252.

[11] OBERPRILLER, B., BURKHARDT, L., GRIESBACH, B. Benchmark 3 - Continuous Press Hardenin, Proc. of Numisheet. 2008, no. 9, pp. 115 - 129.

[12] KIESSLING, R. Untersuchungen zu den werkstoffspezifischen Versagensmechanismen von Widerstandspunktschweißungen unter Crash- und Ermüdungsbeanspruchung, Abschlußbericht, BMWi / AiF-Nr. 14.927 N.

[13] WILZER, J.J., WEBER, S., ESCHER, Ch., THEISEN, W. Material Requirements for Hot Stamping Tools using the Example of Tool Steels X38CrMoV5-3, 30MoW33-7, and 60MoCrW28-8-4. HTM J. Heat Treatm. Mat. 2014, vol. 69, pp. 1-6.

[14] GU, Z.-W., LV, M.-M., LU, G.-H., XU, H., LI, X. Heat transfer coefficient evolution of boron steel during hot forming die quenching. Materials Science and Technology. 2015, vol. 32, no. 2, pp. 173-180.

[15] BEHRENS, B-A., JÜTTNER, S., BRUNOTTE, K., ÖZKAYA, F., WOHNER, W. STOCKBURGER, E. Extension of the Conventional Press Hardening Process by Local Material Influence to Improve Joining Ability. Procedia Manufacturing, 2020, vol. 47, pp. 1345-1352. 